(C) Л.И. Никонова

\title{
ОРГАНИЗАЦИЯ ЖИЗНЕДЕЯТЕЛЬНОСТИ И ФОРМИРОВАНИЕ МОРДОВСКОГО НАСЕЛЕНИЯ НА КРАЙНЕМ СЕВЕРЕ (ПО РЕЗУЛЬТАТАМ ЭТНОГРАФИЧЕСКОЙ ЭКСПЕДИЦИИ)
}

\begin{abstract}
Крайний Север - поликультурный регион, где проживают народы разных национальностей, вт.ч. имордва. С 22 сентябряпо 4 октября 2013 2. состоялась этнографическая экспедиция по маршруту Кайеркан, Дудинка, Норильск, Диксон. Участники экспедиции (Никонова Л.И. - руководитель, Охотина Т.Н., Фадеева М.М.), собирали материал по истории освоения края, провели опрос информаторов согласно плану-проспекту этнографического исследования, сделали фотоснимки (информаторы, документы, статистика). Мордовские переселенцы сумели сохранить элементы традиционной культуры, на что значительно повлияла их непрекращающаяся связь с Республикой Мордовия. Традиции проявляются в нацииональных блюдах, обрядах. Вместе с тем, заметны и нововведения. Северный климат сказался на сочииальном поведении, адаптации этнической специфики к местным условиям, когда культурно-хозяйственные особенности (промысль и занятия), материальная культура (жилище, одежда, пища, народные знания) подчинялись физико-географическим и экологическим условиям, видоизменяя традиции, что можно отнести к особенностям адаптации мордвы в условиях Арктики.
\end{abstract}

Ключевые слова: территории Арктики и Крайнего Севера, мордва, история переселения, экспедиция, историко-этнографическое исследование, традиции, инновации

Крайний Север - это в России часть территории, расположенная преимущественно к северу от Полярного круга. Она включает арктические пустыни, тундровую, лесотундровую и часть таёжной зоны. Эти места характеризуется суровыми климатическими условиями и относительно слабой заселённостью. К районам Крайнего Севера отнесены: Тува, Якутия, Магаданская область, Чукотский автономный округ, Камчатская, Мурманская области, отдельные районы и города Карелии, Архангельской области, Республики Коми, Тюменской области, Хакасии, Красноярского края, Иркутской области, Хабаровского края и Сахалинской области и местности, приравненные к районам Крайнего Севера - отдельные районы и города Бурятии, Томской, Читинской и Амурской областей, Приморского края. С 2001 г этнографы НИИ при Правительстве РМ провели этнографические экспедиции

Никонова Людмила Ивановна - д.и.н., проф., ведущий научный сотрудник отдела этнографии и этнологии ГКУ Республики Мордовия «Научно-исследовательский институт гуманитарных наук при Правительстве Республики Мордовия» (Саранск, ул. Льва Толстого, 3). Эл. почта: congress7@list.ru. Nikonova, Liudmila I. - Research Institute for Human Sciences under the Government of Republic of Mordovia (Saransk, Leo Tolstoy street, 3). E-mail: congress7@list.ru 
в некоторые районы Крайнего Севера: Красноярский (2001) и Приморский (2004) края, Сахалинскую (2004), Камчатскую (2005) и Иркутскую (2008) области; Республику Хакасию, Забайкальский край (2008), Тюменскую, Томскую, Магаданскую области (2009); Республику Саха (Якутия) (2009) (рук. экспед. этнограф, д.и.н. профессор Л. И. Никонова и науч. сотрудники отдела этнологии института). По их результатам изданы книги серии «Мордва России» (см. напр.: Никонова 2004, Никонова 2009 и др.). 22 сентября по 4 октября 2013 г. совершена этнографическая экспедиция в Таймырский Долгано-Ненецкий (г. Дудинка, Кайеркан, Норильск, пгт. Диксон) район (рук. проекта и экспедиции д.и.н., профессор Л. И. Никонова и науч. сотр. отдела Т.Н. Охотина, М.М. Фадеева). Ее целью было изучение истории переселения, факторов адаптации в иной природно-климатической зоне, а в целом системы жизнедеятельности в особо суровой арктической местности.

Каждая культура может быть истолкована как стратегия человеческой адаптации, а каждый элемент уникальной социальной модели как средство для получения из среды обитания максимальной энергии (Лурье 2004: 147). Этот подход предполагает, что вся культура народа, не только материальная, непосредственно связанная с обеспечением жизнедеятельности, но и социальная, и духовная, хотя и не в полной мере, но детерминируется, организуется и структурируется под влиянием стратегии его жизнедеятельности (Лурье 2004: 147). В связи с этим большое значение для исследования имела литература, содержащая сведения о природно-климатических условиях исследуемого региона, играющих важную роль в адаптации переселенцев на новом месте; труды отечественных ученых, путешественников, краеведов, представляющие собой общетеоретическую основу (см. напр.: Кривоногов 1998, Бородина 2012 и др.). В качестве сравнительного материала привлечены работы ученых, занимающихся изучением здорового образа жизни в северных широтах (см. напр.: Василенко 1987, Хаснулин 1999, Яптунэ 2004 и др.). Проведенный обзор литературы свидетельствует о том, что, несмотря на наличие ряда научных работ, культура мордвы, проживающей на исследуемой территории, до настоящего времени не была предметом специального изучения и недостатки конкретной информации о мордве, проживающей в арктической зоне Крайнего Севера компенсируются авторскими полевыми (ПМА 2013: Диксон, Дудинка, Кайеркан, Норильск) и некоторыми архивными материалами (Архив. Диксон: Оп. 5. Культура. Д. 05-05. 2013).

Натерриториипоселений,гдепроживаютпредставителиразныхнациональностей, в т.ч. и мордва, успешно реализуются региональные и муниципальные программы развития и поддержки социальной сферы и этнокультуры, что жизненно важно для приезжего населения. Включаясь в инокультурную среду на новом месте, они проходят процесс адаптации со всем блоком составляющих компонентов традиций, основных укладов хозяйства, быта.

Таймырский (Долгано-Ненецкий) муниципальный район является частью Красноярского края, где в территорию района (2010 г.) входят г. Дудинка, п. Диксон, Норильск как город краевого подчинения и Кайеркан - район Норильска (см. напр. Таймырский Долгано-Ненецкий район и др.).

Исходя из имеющихся сведений видно, что динамика численности мордвы в изучаемом районе имеет общие тенденции, свойственные славянским, тюркским и северным народам. Наибольшей была численность мордвы здесь в 1939 г., затем она постепенно падала до 1959 г., что связано с особыми проходившими в стране истори- 
ческими событиями, которые серьезно повлияли на изменения в социальной сфере. С 1959 по 1979 гг. у мордовского населения отмечено повышение численности, свидетельствующее об увеличении рождаемости, что характерно для демографической ситуации по стране в целом. Резкий спад численности происходит уже с 1980-х гг. и продолжается до настоящего времени (данные переписи 2010 г.), на что повлияли серьезные изменения в экономике страны, которые произошли за данный период.

Таблица 1

\section{Численность мордвы в Таймырском (Долгано-Ненецком) муниципальном районе}

\begin{tabular}{l|l|l|l|l|l|l|l}
\hline Год & $\mathbf{1 9 3 9}$ & $\mathbf{1 9 5 9}$ & $\mathbf{1 9 7 0}$ & $\mathbf{1 9 7 9}$ & $\mathbf{1 9 8 9}$ & $\mathbf{2 0 0 2}$ & $\mathbf{2 0 1 0}$ \\
\hline Численность, человек & 158 & 58 & 94 & 127 & 65 & 87 & 57 \\
\hline
\end{tabular}

* Таблица составлена по: Демоскоп Weekly; Национальный состав 2005: 91.

Согласно проведенному опросу информаторов в результате этнографической экспедиции основными причинами переселения мордовского населения из Республики Мордовия на исследуемую территорию являлась существенная социальная поддержка со стороны государства: предоставлялось жилье (ПМА 2013: Молева, Корюкова, Ломовцева, Надькина, Корюкова, Ломовцева), оплачивался проезд, провоз багажа и выдавались подъемные деньги; в детском саду, школе и на вредном производстве бесплатно предоставлялось молоко; регулярно выплачивалась заработная плата, оформлялась льготная пенсия (ПМА 2013: Корюкова, Корюков, Молева), вырабатывалась льгота районного коэффициента и процентных надбавок к заработной плате «полярки» (ПМА 2013: Корюкова).

Дудинка - самый северный город планеты, административный центр Таймырского Долгано-Ненецкого муниципального района. Он расположен в низовьях реки Енисей более чем в 2500 км от Красноярска (Красноярский край 1984: 356). Дудинкасовременный город с развитой инфраструктурой, все объекты которой - школы, больницы, детские сады, жилые дома - возведены на вечной мерзлоте. В городе действуют спортивный комплекс, плавательный бассейн, кинодосуговый центр, детско-юношеская спортивная школа и школа искусств, Таймырский краеведческий музей (с 2009 г.). Здесь проживают представители более шестидесяти различных национальностей: ненцы, долганы, энцы, нганасаны, эвенки и др. (Дудинка 1997). На 1939 г. в Дудинском районе из общей численности населения - 18826 чел. русских - 13 454; украинцев - 1 663; якутов - 458; белорусов - 398; татар - 319 чел. и пр. народностей, мордва на 10 месте и ее численность - 135 чел. В с. Дудинка (окрц/ рц) на 1939 г. из общей численности населения - 3568 чел. русских - 3094 ; украинцев - 157; татар - 68; якутов - 49; белорусов - 31; мордвы - 25 чел., и это 6 место по численности (Демоскоп: элект ресурс). На 2002 г. в Дудинке - 72 чел. мордвы, что составляет 0,2 \% ко всему населению. Мордовское население переехало: по причине поиска хорошей работы (родители), либо проживают здесь с рождения (дети ранее приехавших родителей). Так, Е.К. Евай работает главным специалистом в МБУК Городской центр народного творчества; В.А. Попков в службе транспортного обеспечения администрации. Здесь же живут и другие представители мордвы: Н.В. Русских (Рой), Н.В. Некипелова (Лизина). Их история переселения разная. Так, Л.И. Томашевская, рассказала, что родом она из пос. Курагино Красноярского края, 
но ее бабушка мордовка А. Н. Мочалова, 1917 г. р. до 1945 г. жила в Мордовии, а потом уехала в Норильск. В Дудинке живет и ее сестра Т. И. Деменева. Н.С. Филипповская родилась в с. Верхняя Коя Красноярского края, в Дудинке живет с 2002 г., работает главным специалистом отдела клубной работы и досуговой деятельности по работе с детьми КГБУК «Таймырский Дом народного творчества». Здесь также живут ее мама Г.П. Филипповская (Вирясова) и мамины сестры: Л.П. Склярова (Вирясова) и 3. П. Халевина, родом они из Зубовополянского района Мордовии.

Национальный состав в Норильске на начало 2000-х гг. в основном представлен русскими, украинцами, азербайджанцами и др. В настоящее время население Норильска почти целиком состоит из людей, переехавших в город во второй половине XX в. и их потомков. Представителей коренных национальностей (ненцы, энцы, нганасаны, долганы) в городе мало. В Норильске на 1939 г. общая численность населения составляла 13886 чел., из них русских - 9788 чел.; украинцев - 1492; белорусов - 364; евреев - 305; татар - 237; немцев - 204 чел. и пр. Мордва при численности в 109 чел. находится на 9 месте. Ныне основными причинами переселения информаторов в г. Норильск является возможность получить хорошо оплачиваемое рабочие место (ПМА: Норильск) или работу вахтовым методом. Так, И.Н. Куркин работал в МВД, после выхода на пенсию - в администрации города, сейчас - консультант-юрист экспертно-правового отдела Норильского городского Совета депутатов. Его жена Ю.Г. Куркина (Шестина) работает в МВД, капитан ОП № 1, дознаватель. А.А. Шатров ранее работал в МВД, сейчас на пенсии. С.Н. Юдин работает в фирме «Иландорильск». Опрошенные приезжали с 1990-х гг.: с 1997 г. А.А. Шатров; в 2003 г. - И.Н. Куркин; в 2009 г. - С Н. Юдин. До сих пор проживают в Ноорильске.

Кайеркан - район г. Норильска (Кайеркан: эл ресурс). Через Кайеркан проходят железная дорога и автомобильное шоссе Толнах - Норильск - Дудинка (Кайеркан, энцикл.: 36). В Кайеркане представлена мордва из г. Рузаевка Мордовии (с 2011 г.) .

Основные причины переселения мордовского населения на Диксон, согласно проведенному опросу, это - приглашения, вызовы и распределение, по объявлению (требуются специалисты), добровольное переселение к родственникам и др. Так, по приглашению Е.А. Тимониной переехала И.А. Ломовцева; В.А. Табаковой Л.А. Куркина, Н.Н. Фадеева, Е.А. Надина; И.В. Корюковой - Мамаевы, Ванюшкины; по распределению - Э.О. Корюков; Т.Н. Белоусова; по объявлению (требуются специалисты) - Е.А. Тимонина; по семейным обстоятельствам - Г.В. Николаева; к родственникам - М.И. Молева, В.А. Табакова (к тёте Т.А. Савельевой), Н.В. Соколов (к Л.А. Куркиной). Согласно опроса информаторов переселение происходило в следующие года: 1963 г. - М.И. Молева; 1967-1968 гг. - Т.А. Савельева; 1982 г. Т.Н. Белоусова, В.Н. Клименова; 1983 г. - В.А. Табакова; 1994 г. - Е.А. Надина. Основная волна переселения приходится на 2000-е года, так в 2000 г. переехали Корюковы; 2003 г. - Л.А. Куркина, Н.В. Соколов; 2004 - Мамаевы; 2005 - М.В. Конищева, Н.Н Фадеева; в 2007- Е.А. Тимонина; 2010 - Г.В. Николаева; в 2013 г. И.А. Ломовцева, Ванюшкины.

Значимым фактором для выявления особенностей материальной и духовной культуры переселенцев является рассмотрение мест их выхода, т.е. территорий с которых они выезжали. Большее их число родились в населенных пунктах Республики Мордовия и Красноярского края. Так, И.Н. Куркин, Н.Н. Фадеева, М.Е. Фадеев приехали из Саранска; Г.П. Филипповская - д. Калиновка Ширингушского (ныне 
Зубово-Полянского) района РМ; А.В. Чадин, Э.О. Корюков, И.А. Ломовцева, В.В. Конищев, Е.А. Тимонина, Ванюшины - г. Рузаевка; И.В. Корюкова - с. Левжа Рузаевского района; В.А. Табакова, Т.А. Савельева, Л.А. Куркина, Е.А. Надина - с. Мордовская Пишля Рузаевского района. Из населенных пунктов Красноярского края, в том числе из г. Норильска - Ю.Г. Куркина; пос. Курагино - Л.И. Томашевская; с. Верхняя Коя Н.С. Филипповская; с. Черна Кояну Красноярского края - Н.В. Некипелова.

Среди опрошенных встречались уроженцы и переселенцы их городских и сельских населенных пунктов различных областей России. Так, из г. Приморско-Ахтарск Краснодарского края В.А. Попков; г. Орск Оренбургской области - С.Н. Юдин; д. Огибь Устюженского района Вологодской области - М.И. Молева; г. Мичуринск Тамбовской области - Т.Н. Белоусова; из пос. Нижний Уфалей Верхнеуфалейского района Челябинской области - А.П. Мамаев; г. Балаково Саратовской области В.Н. Клименова. Также родом из Казахстана М. В. Конищева, родилась на Украине Н.В. Русских (ПМА).

Некоторые опрошенные имеют родственную связь с выходцами из Мордовии или какое-то время работали там. Так, бабушка Л. Томашевской по национальности мордовка - А.Н. Мочалова, 1917 г.р., она до 1945 г. жила в Мордовии, а потом уехала в Норильск. Мама Н.С. Филипповской - Г.П. Филипповская (Вирясова), 1953 г.р. родом из Зубово-Полянского района РМ. Отец С.Н. Юдина - Н.В. Юдин, родом из с. Никитино Ардатовского района РМ. А.П. Мамаев в г. Рузаевке РМ работал главным специалистом отдела ЖКХ в Администрации в 1981 г. М.В. Конищева работала в г. Рузаевка РМ завучем по учебной работе в лицее №4.

Профессиональная деятельность информаторов на Диксоне разнообразна: есть среди них рабочие, повара, служащие и др. По воспоминаниям старожилов пгт Диксон при Морском порту раньше были коровники, свинарники, теплицы (ПМА 2013: Молева). Как писала газета «Советский Таймыр» от 20 января 1982 года, «Молочнотоварная ферма на Диксоне, расположенная за 73-й параллелью, самая северная в нашей стране. Нелегок труд животноводов, работающих в суровых арктических условиях» (Иванов 1982). Здесь, дояркой работала Т.А. Савельева (Костина) приехавшая на Диксон (1967 - 1968 гг.) с мужем Александром Ивановичем, который работал строителем в порту (ПМА 2013: Табакова). М.И. Молева (с 1963 г.) трудилась на складе, а муж В. А. Молев - на гидробазе; В. А. Табакова (Надина) - бригадиром в столовой (с 1983 г.), а ныне крупный частный предприниматель. Е.А. Надина продавец в магазине; Л.А. Куркина (Надина) (на Диксоне с 2005 г.) - генеральный директор пекарни ОО «Арктика»; Н.Н. Фадеева (Куркина) - юрист (морской порт, с 2004 г.), ныне - начальник территориального пункта УФМС России по Красноярскому краю. А.П. Мамаев работает в культурно-досуговом центре (КДЦ), О. Мамаева - бухгалтер администрации пгп. Диксон (с 2003 г.). Е.В. Ванюшкина специалист по культуре КДЦ (с 2013 г.), а муж А.А. Ванюшкин - администратор базы данных Администрации Диксона. И.А. Ломовцева - ныне директор МКОУ «Диксонская ДШИ», преподает сольфеджо, музыкальную литературу, хоровое и сольное пение; М.В. Конищева (Бикмаева) - преподаватель в художественном отделении «Диксонской ДШИ» (с 2005 г.), её дочь Алена Валерьевна - работает в Дудинке помощником генерального директора организации ООО «ТаймырЭнергоКом». Е.А. Тимонина, преподаватель музыки (с 2007 г.) (ПМА 2013). 
Множество факторов оказывает влияние на облик культуры: сказывается изменение климата, перемещение в другие природные условия, культурные контакты с соседними народами, предыдущий культурный опыт и традиции. Переселившись на Крайний Север, мордовские переселенцы вступали в контакт с местными жителями и заимствовали у них многое из того, что необходимо для жизнеобеспечения и социальной организации в зоне Крайнего Севера. Так, в суровых условиях жилище является одним из главных способов освоения природной среды: конструктивные особенности дома, тип усадьбы и поселения в целом демонстрируют в предметнопространственном воплощении особый образ жизни населения в районах Севера (Пермиловская 2014: эл ресурс).

Например, жилищное строительство в Норильске велось на многолетнемерзлых грунтах с применением свайных железобетонных фундаментов (Северная энцикл. 2004: 662). Само название города происходит от юкагирского слова, означающего «топкий берег», «болото» (Города России 2008: 321). Здесь улицы располагаются перпендикулярно направлению ветра, для ослабления его силы устроены перепады уличных осей. Жилые кварталы построены без разрывов, сплошным домом, выходящим на все четыре улицы, что способствуют созданию «ветровой тени», защищающей дворы от пурги и метелей (Города России 2008: 321). Внутри дворов стоят школы, детские сады, ясли. В домах теплые, уютные, полностью благоустроенные квартиры (Касноярский край 1984: 354). Городская застройка Кайеркана отличается своеобразной компактностью: внутренняя часть города как бы ограждена от пурги 9-этажными домами, образующими круг и ослабляющими силу ветра (Города России 1994: 169). Диксон Таймырского (Долгано-Ненецкого) муниципального района (Городское поселение Диксон 2012: 8) расположен на берегу Енисейского залива Карского моря (Города России 1994: 119-120). Часть территории городского поселения в соответствии с Приказом Федеральной службы безопасности Российской Федерации от 29 мая 2007 г. № 273 «О пределах пограничной зоны на территории Красноярского края» отнесена к пограничной зоне с соответствующим режимом (Генеральный план 2012: 5).

Успешность адаптации мордовского населения в арктических условиях, напр. в пгт. Диксон, нашла выражение в принципах формирования жилой среды, наиболее близкой к быту и повседневным потребностям человека. Ясное зонирование поселения, выделяющее жилую застройку, административный, торговый и культурный центр, а также многофункциональность зданий различного назначения обеспечили удобство и рациональность поселения (Майничев: электр рес.). Здесь жилая застройка представлена: 3- и 5-этажными капитальными зданиями (5 домов по ул. Воронина и 2 дома по ул. Водопьянова (Гор. пос. Диксон 2012: 14), 2- и 3-этажными деревянными и арболитовыми домами (по ул. Водопьянова и ул. Таяна) (Генеральный план, Диксон 2013: 6). Общественно-деловая зона в основном сформирована в центральной части поселка между улицами Водопьянова и Таяна. Здесь, вокруг поселковой площади, концентрируются наиболее значимые социальные и культурные объекты поселка - Администрация городского поселения, культурно-досуговый центр, библиотека, картинная галерея, школа, детское дошкольное учреждение, торговый центр, узел связи, детские площадки. На центральной площади также расположены недавно построенное здание Церкви Николая Угодника (по инициативе предпринимателя В.А. Табаковой) и памятник 
известному исследователю Таймыра Н.А. Бегичеву. Отдельно (в конце ул. Таяна) расположена площадка больницы с поликлиническим отделением (Гор. пос. Диксон 2012: 14). В поселке имеются два кладбища: закрытое для захоронений и действующее (Гор. пос. Диксон 2012: 13). По словам А.П. Мамаева, кладбище образовано в 1960-х гг. и на его территории находится так называемая «линза», из-за этого ползет земля (ПМА 2013:Диксон) и ледники примерно через 20 лет «выдавливают» гробы из земли (ПМА 2013: Диксон), поэтому за могилами постоянно следят: засыпают щебнем или камнем (ПМА 2013: Диксон).

В г. Дудинка и пгт. Диксон вдоль улиц, застроенных домами, тянутся деревянные мостки-тротуары с поручнями. Бытовые коммуникации в пгт. Диксон - изолированы и покрыты деревянными чехлами (Чаган 1976: 186), которые по воспоминаниям М.И. Молевой стали делать с 1980-х. гг. (ПМА 2013: Диксон). Трубопровод утепляют стекловатой, либо засыпают шлаком или дробленным углем и закрывают дощатым коробом. По сведениям, полученным от информаторов, электричество проведено в каждую квартиру, но запасают и свечи - здесь мощная пурга (по-местному их называют - «черные пу́рги»), которая может порвать провода или повалить столбы (Чаган 1976: 187).

Традиционные изделия или предметы в стандартной квартире выступают в качестве украшения и деталей интерьера, то есть происходит трансформация их функций - из утилитарной в декоративную. У всех опрошенных информаторов в интерьере квартир присутствуют различные предметы с мордовской тематикой: магниты с изображением герба или флага Мордовии, статуэтки и куклы в национальных костюмах, разнообразные салфетки, старинные полотенца (повсеместно) (ПМА 2013: Диксон, Дудинка, Кайеркан). У мордовского населения на иноэтничной территории обитания продолжается частичное функционирование традиционных верований и обрядов, связанных с жилищем. Например, по обычаю в новую квартиру первой запускают кошку (ПМА 2013: Диксон), верят в переселение духов в новый дом из старого места жительства (Харючи: электр. ресурс ; ПМА 2013 : Диксон).

Важным для успешной адаптации к экстремальным условиям Крайнего Севера является организация правильного питания пришлого населения, которое компенсирует отрицательное воздействие климата на организм. Так, по словам М.И. Молевой, приехавшей в пгт Диксон в 1963 году, для жителей была предусмотрена еда в столовой: сало, колбасы, рыба, хлеб, овощи, а на обед всегда давали горячее первое и второе. Дома готовили мало - было некогда, работали в три смены, особенно в период навигации. В Арктической зоне растительная пища служила лишь подспорьем и приправой, а главную роль в питании играли продукты животного происхождения (мясо и рыба). Так, по словам Е. В. Ванюшкиной мясо оленя используют в пищу обычно зимой (Диксон) и в нескольких видах: свежее, свежемороженое (строганина), копченное или сушенное мясо. Приехав сюда, мордовские переселенцы ввели в свой рацион питания оленину. Так, при вопросе о том, что помогло адаптироваться в новых суровых северных условиях, информаторы отвечают, что оленина и рыба, которые добывают на охоте, рыбалке или покупают у индивидуальных предпринимателей, промысловиков (Диксон). Среди мордвы охотой и рыболовством занимались А.П. Мамаева, Э.О. Корюкова и др. Мордовские переселенцы переняли опыт приготовления оленины у приехавших 
ранее жителей. Из оленины готовят первые и вторые блюда, рубленные, натуральные бифштексы, варят кусками, тушат, жарят, маринуют, использует и как фарш для пельменей, делают холодец, буженину (ПМА 2013: Диксон). В качестве деликатеса мордовские переселенцы употребляют сушено-вяленное мясо северного оленя юкалу (ПМА 2013: Кайеркан). Готовят мордовские переселенцы и пельмени. Их делают традиционно по-мордовски - большими (повсеместно). На севере в рационе питания мордовских переселенцев основное место занимает, по их словам, рыба омуль, сайка, хариус, синявка, горбуша, нельма, чирик. Её варят, жарят, припускают, тушат, консервируют, солят, вялят, коптят, сушат. По рассказам информаторов, они также стали готовить строганину, в основном из сика и чира. Блюда из дичи (куропатки, утки, гуся) вносят в меню большое разнообразие. Дичь тушат, жарят, делают шурпу (ПМА 2013: Диксон, Норильск, Дудинка).

Еда с использованием муки, различная выпечка - традиционна для мордовского населения и здесь они не изменяют своим традициям: пекут пироги с различной начинкой, блины (ПМА 2013: Норильск), а по выходным - «кургане» (Диксон); небольшие лепешки с открытой начинкой, подобные русской ватрушке с творогом, мятым картофелем (ПМА 2013: Дудинка, Нрильск, Диксон); толстые пшенные блины «пачат» (ПМА: Диксон, Кайеркан, Норильск, Дудинка). Арктическая флора представлена главным образом мхами и лишайниками, хотя известно около 500 видов трав и кустарников, произрастающих в этом регионе (Месштыб 1999: 68). Грибы ходят собирать в тундру (ПМА 2013: Дудинка).Мордва употребляет грибы типа волнушек, но местные называют их груздями, сыроежками (ПМА 2013: Дудинка); солят грибы по-мордовски: слоями выкладывает грибы и соль, покрывая сверху лопухом (ПМА 2013: Диксон). Мордовские переселенцы на севере собирают бруснику, кислицу, голубику (ПМА 2013: Дудинка), ягоды которых замораживают. Капусту покупают и квасят в кадках (ПМА 2013: Диксон).

Для чая и на случай простуды запасают и привозят из Мордовии травы: зверобой, липовый цвет, крапиву, ромашку, полынь, тысячелистник. Для профилактики заболеваний ежедневно заваривают чай и обязательно с чабрецом. Как говорят в семьях: «чай без чабреца, это не чай» (повсеместно). Из напитков распространен квас (ПМА 2013: Диксон, Дудинка).

Большое значение у мордвы придается традиционным праздничным блюдам: голубцам, пирогам и холодцу (из оленины). Диксонская мордва на престольный праздник - Рождество Божьей Матери (21 сентября), характерный для села Мордовская Пишля откуда они родом, пекут мордовские блины «пачат» (ПМА 2013: Диксон).

Здоровая и полезная пища должна быть, прежде всего, свежей, поэтому создают все условия для хранения продуктов. Например, на Диксоне для большого количества продуктов частные лица арендуют склады-мерзло́тники, расположенные на юге пгт. Диксон. Запасов в виде консервированных солений не делают. Варенье, мед привозят из Мордовии (ПМА 2013: Диксон).

История изучения праздников у мордвы показывает, что они всегда были тесно связаны с условиями жизни людей, со способами добывания основных средств их существования, с формированием и развитием мировосприятия и верований. По словам М.И. Молевой (Диксон), мордва, как и другиенароды Севера, раньше отмечали Новый год и все советские праздники. Сейчас - Рождество и Пасху (ПМА 2013: Диксон). После Нового года и Рождества начинаются Святки, продолжающиеся 
вплоть до Крещения. Традиционно на Святках устраивают катания с гор, игры, гадания и т. д. Обязательно на праздник много ряженных, ходящих по домам, исполняющих песни-колядки о семейном благополучии, здоровье, плодородии и т. д. Здесь на Святках раньше гадали, подслушивали: хорошие речи в пользу, дурные не к добру. Падали спиной на снег: хороший отпечаток- выгодно, не совсем - плохо (Город у Красноярского яра 1986: 2016). На Рождество (Диксон) по традиции дети наряжаются, разукрашивают лица и ходят колядовать: «Коляда, Коляда, отворяй ворота! Отворяйте сундуки, доставайте пятаки!» За колядку детям дают конфеты, фрукты, выпечку или деньги (ПМА: Диксон). Информаторы отмечают, что сейчас на Рождество наряжаются не только дети, но и взрослые: надевают парики, делают маски и т. д. (ПМА 2013: Диксон).

На Масленицу (2-половина февраля) мордовская молодежь раньше переодевалась, надевала маски и ходила из дома в дом с традиционными мордовскими блинами и «закличками»: «Подходите, подходите! Поиграйте, посмотрите! Не пугайтесь, не стесняйтесь, веселитесь, развлекайтесь!» (Архив. Диксон. Оп. 5. Культура. Д. 05 05). Ныне вместо Масленицы (в первое воскресенье февраля) отмечают «Праздник Солнца» (в народе - «День Солнца») - встречи вернувшегося после долгой полярной ночи солнца ПМА: Диксон). В этот день сжигают чучело «поляной ночи» (ПМА 2013: Диксон).

Многие информаторы помнят престольные праздники из мест выхода и продолжают отмечать их на Крайнем Севере. Так, у В. А. Табаковой, Л. А. Куркиной, Е. А. Надиной, И. А. Ломовцевой и др. престольный праздник приходится на 21 сентября - «Рождество Пресвятой Богородицы». В этот день на Диксоне мордовские жители пекут блины, пироги и собираются с родственниками (ПМА 2013: Диксон). В Дудинке 21 сентября отмечают «День финно-угорских предков», приуроченный ко дню Осеннего Равноденствия (ПМА: Никепелова).

Как известно, семейная обрядность является одним из наиболее устойчивых компонентов народной культуры. Обряды наряду с обычаями и традициями, выполняют роль регулятора национальной жизни, ее упорядоченности и организации (Иванова: элект ресурс). Свадьбы мордвы на исследуемой территории проходят в основном по русским традициям (ПМА 2013: Диксон, Дудинка), но желают молодым счастья, как правило, на мордовском языке, а под ноги жениха и невесты стелят старинное мордовское полотенце, тулуп, приговаривая, что это для благополучия и богатства (ПМА 2013: Диксон). Здесь также соблюдаются обряды, направленные на деторождение, например, обсыпание молодых зерном или хмелем с присказками также на родном мордовском языке (ПМА 2013: Диксон, Дудинка). Детей крестили «на материке», а после постройки церкви на Диксоне стали крестить здесь. Особо важная роль в проведении крестин отводится крестным родителям, кума готовит подарки ребенку: рубашку, крест, шапочку, пояс и пеленку, в которую принимают ребенка от попа после купели.

Похоронно-поминальныеобрядыусловноможноразделитьнапредохранительные, похоронные и поминальные. Элементы предохранительных обрядов мордвы в значительной степени схожи с традициями многих народов Севера. Так, жилище, где умер человек, считалось «нечистым», поэтому, после выноса гроба с покойным из дома обязательно мыли полы (ПМА 2013: Диксон). Нганасаны, ненцы и другие народы Севера поворачивали передок нарт умершего с южного или восточного на- 
правления на север или запад. «Чтобы дом не развалился», его обвязывали снаружи тонкой веревкой или ниткой (Северная энциклопедия 2004: 769). Традиционно же у мордовского населения в качестве предохранительных и очистительных предметов использовали железные предметы: нож, топор, ножницы и др. (Мордва, 1995: 257). «Чтобы души живых не были уведены мертвецами» все ночи до похорон, а иногда и до 40 дней, в жилище мордвы как и других народов Севера должен был гореть свет (Северная энциклопедия 2004: 769). Умерших людей их родственники стараются вывозить «на материк», редко кто здесь хоронит, т. к. вечная мерзлота со временем выталкивает гроб на поверхность земли. По словам информаторов, если же хоронят людей на Севере, то стараются хоронить рядом с умершими родственниками (ПМА 2013: Дудинка). Поминальные трапезы проводят также на родине умершего.

Таким образом, мордовские переселенцы, попавшие на крайний Север в крайне непривычные и суровые условия по сравнению с условиями средней полосы России, сумели сохранить элементы традиционной культуры, но в нее добавлены и серьезные нововведения. Мордовское население, проживающее на исследуемой территории, переезжало в уже существующие населенные пункты со смешанным составом жителей, поэтому для современных жилищ мордвы Арктики характерна утрата этнической специфики, как элемента традиционной материальной культуры, но при этом в них наглядно проявляется адаптация этноса к новым географическим и социальным условиям. Изменения в семейной обрядности мордвы в этой местности привели к формированию измененного и более простого комплекса народной культуры. В тоже время в семейных обрядах наблюдается сохранение некоторых традиционных черт, на что значительно влияет связь с Республикой Мордовия. Традиции проявляются в национальных песнях, питании. Мордовские переселенцы восприняли от местных жителей обычай сыроедения замороженных продуктов, но сумели сохранить некоторые традиционные блюда. Частично сохранившийся традиционный календарь, состоящий из православных и календарных праздников, во многом общерусский, имеет ощутимое сходство у всех жителей края: праздничное поведение, гуляния с играми и развлечениями молодежи, танцы и сопровождающие их песни, но мордва исполняет их на родном языке. Северный климат влиял на формирование специфики культурно-хозяйственных особенностей (промыслы и занятия), материальной культуры (жилище, одежда, пища, народные знания), которые подчинялись физико-географическим и экологическим условиям, видоизменяя традиции различных этнических групп проживающих и переселившихся на данные территории, на их социальное поведение, стирая отличия, целью чего является адаптация и выживание в Арктике.

\section{Источники и материалы}

Архив. Оп. 5. Культура. Д. 05-05 - Архив Администрации городского поселения Диксон. Оп. 5. Культура. Д. 05-05. Годовые отчеты о работе учреждений культуры городского поселения Диксон.

Архив Оп. 5. Культура. Д. 05-14 - Архив Администрации городского поселения Диксон. Оп. 5. Культура. Д. 05 - 14. Историческая справка администрации городского поселения Диксон // Документы (исторические и тематические справки, обзоры, подборки публикаций в средствах массовой информации, фотодокументы, видеодокументы).

Генеральный план 2012 - Генеральный план городского поселения Диксон. Перечень основных факторов риска возникновения чрезвычайных ситуаций природного и техногенного характера. СПб. Т. 2. 2012. 124 с. 
Генеральный план 2013 - Генеральный план городского поселения Диксон // Диксонский Вестник. 21 августа 2013 г. № 24 (235). 15 с.

Город у Красного яра 1986 - Город у Красного яра: Документы и материалы по истории Красноярска первой половины XIX в. / Сост. и автор комментариев Г.Ф. Быконя. Красноярск: кн. изд-во, 1986. 320 с.

Города России 2008 - Города России: энциклопедия / под ред. Г.М. Лаппо. Репр. изд. М.: Научное издательство «Большая Российская энциклопедия», Дрофа, 2008. 559 с.

Городское поселение Диксон 2012 - Городское поселение Диксон. Таймырский ДолганоНенецкий муниципальный район. Красноярский край. Генеральный план поселения. Пояснительная записка. Материалы по обоснованию проекта. СПб. Т. 1. 2012. 173 с.

Иванов 1982 - Иванов Б. Эффект подсобного хозяйства // Советский Таймыр. 20 янв. 1982 г. Кайеркан 2020 - Кайеркан. http://ru. org/ /\%CA\%E0\%E9\%E5\%F0\%EA\%E0\%ED.

Комарова 1992 - Комарова (Ненянг) Л. Спасение - в народной медицине (Ненецкие верования, традиции, обычаи): [Народная медицина ненцев] // Сов. Таймыр. 1992.18 апр.

Красноярский край 1984 - Красноярский край: Справочник / сост.: О.А. Хонина, Р.Л. Иванова. Красноярск: кн изд-во, 1984. 360 с.

Национальный состав 2002 - Национальный состав населения Республики Мордовия. Итоги Всероссийской переписи населения 2002 г.: стат. сб. Саранск: Территориальный орган Федеральной службы государственной статистики по РМ, 2005. № 932.97 с.

Норильск 2020 - Норильск. http://ru. \%CD\%EE\%F0\%E8\%EB\%FC\%F1\%EA.

ПМА 2013 - Полевые материалы экспедиции автора в Т-ский (Долгано-Ненецкий) p-н Красноярский край, сентябрь 2013 г., пгт. Диксон (информанты: Т.Н. Белоусова, 1957 г. р.; А.А. Ванюшкин, 1982 г.р.; Е.В. Ванюшкина, 1982 г.р.; Н.С. Городенко, 1977 г.р.; Л.А. Кирюхина (Надина), 1963 г.р.; М.В. Конищева (Бикмаева), 1968 г.р.;И.В. Корюкова (Кравчукова), 1969 г.р.; Л.А. Куркина (Надина), 1972 г.р., И.А. Ломовцева, 1963 г.р.;А.П. Мамаев, 1975 г.р.; О.В. Мамаева, 1976 г.р.; М.И. Молева,1932 г.р.; Е.А. Надина, 1964 г.р.; Т.И. Надина, 1964 г.р.; Г.В. Николаева, 1946 г.р.; В.А. Табакова (Надина), 1959 г.р.; Н.Н. Фадеева (Куркина), 1981 г.р.; Г.П. Филипповская (Вирясова), 1953 г.р.); г. Дудинка (информанты: А. Н. Лизина (Пьяных), 1947 г.р.; Н.В. Русских (Рой), 1976 г.р.; Л.П. Склярова, 1970 г.р.; Л.И. Томашевская, 1961 г.р.; З.П. Халевина, 1967 г.р.),пгт. Кайеркан (информанты: Е.К. Евай, 1983 г.р.;В.А. Попков, 1972 г.р.; А.В. Чадин, 1984 г.р.),Норильск (информанты: И. Н. Куркин, 1978 г.р.; Ю.Г. Куркина (Шестина), 1985 г.р.; С.Н. Юдин, 1974 г. р.).

Таймырский 2020 - Таймырский Долгано-Ненецкий район. Официальный сайт.URL: http:// www.vokrugsveta.ru/vs/article/424/.

Демоскоп Weekly - Приложение. Переписи населения (1939, 1959, 1970, 1979, 1989, 2002, 2010). http://www.demoscope.ru/weekly/ssp/rus_nac_..._ra.php.

\section{Литература}

Бородина А.Б. Эстетический анализ декоративно-прикладного искусства русского Севера. Автореф. дис. на соиск. учен. степ. к.филос. н. М.: Рос. гос. ун-т туризма и сервиса, 2012.

Василенко Б.И. Народная медицина и охрана здоровья (на примере Ямало-Ненецкого автономного округа): автореф. дис. на соиск. учен. степ. канд. мед. наук. М., 1987.

Иванова В.С. Обрядность северных манси в конце XIX - начале XXI века: локальные особенности. Автореф. дисс. ... к.и.н. Санкт-Петербург: Музей антропологии и этнографии им. Петра Великого (Кунсткамера) РАН, 2009.

Реданский В.Г. (науч. ред). Диксон - снежной Арктики столица: сборник статей /. Москва: Красноярское книжное издательство, 2005. 176 с.

Вощенкова В. (лит. обраб. и стихи); Лазарев С. (фот.) и др. Дудинка. Город под полярной звездой: Альбом. 1667-1997. М.: Полиграфвидео, 1997.

Сакиева А.А., Юрченко Н.О., Попова А.Н. Коренные малочисленные народы Таймыра: 
традиции, быт, культура: Рекомендательный указатель литературы. Красноярск: ООО Изд-во «Красноярский писатель», 2005. 288 с.

Кривоногов В.П. Этнические процессы у малочисленных народов средней Сибири. Красноярск: изд-во КГПУ, 1998. 320 с.

Санги В.М. Легенды и мифы Севера: Сборник / вступ. статья А.В. Пошатаевой; Худож. В. Петров. М.: Современник, 1985.

Славин С.B. (отв. ред.) Летопись севера. Сборник по вопросам истории экономического развития и исторической географии Севера. Т. 10. М.: Изд-во «Мысль», 1982.

Лурье С.В. Историческая этнология: учеб. пособие для вузов. М.: Аспект-Пресс, 1997. 448 с. Майничева А.Ю. Русские Сибири: зодчество в аспекте этнокультурной адаптации. XVII $\mathrm{XX}$ вв. [Электронный ресурc]. URL: http:www.dissercat.com/content/russkie-sibiri-zodchestvo-v-aspekte-etnokulturnoi-adaptatsii-xvii-xx-vv.

Месштыб Н.А. Растительный мир в аборигенных культурах Арктики (по полевым материалам) // Сибирский этнографический сборник. М., 1999. Вып.9. С.72 - 73.

Никонова Л.И. [и др.] Мордва юга Сибири / под ред. Д.и.н., проф. В.А. Юрченкова; д.и.н., проф. Л.И. Никоновой; НИИ гуманитар. наук при Правительстве РМ. Саранск, 2007. 312 с.

Балашов В.А. (отв. ред.), Брыжинский В.С., Ефимов И.А. Мордва: Историко-культур. очерки / рук. авт. коллектива ак. Н.П. Макаркин. Саранск: Мордов. кн. изд-во, 1995. 624 с.

Мухачев A. Народное врачевание ненцев: [Народные методы лечения болезней ненцами] // Мир Севера, 2002. № 5. С. 72-75.

Никонова Л.И., Щанкина Л.Н., Авдошкина Н.Н., Савка В.П. Мордва Дальнего Востока /под ред. д.и.н., проф. В.А. Юрченкова; НИИ гуманитар. наук при Правительстве РМ. Саранск, 2010. $312 \mathrm{c.}$

Никонова Л.И., Щанкина Л.Н., Гармаева Т.В. Мордва циркумбайкальского региона и Республики Хакасия/под ред. д.и.н., проф. В.А. Юрченкова, д.и.н., проф. Л.И. Никоновой. Саранск: НИИ гуманитарн наук при Правительстве Республики Мордовия, 2010. 268 с.

Никонова Л.И., Щанкина Л.Н., Шерстобитова Ж.В. Мордва Западной Сибири: в 2 ч. Ч. 1. Село Калиновка: сибирская история и мордовские традиции / под ред. д.и.н., проф. В.А. Юрченкова. Саранск, 2009. 112 с.

Пермиловская А.Б. Семантика крестьянского дома в культуре Русского Севера: XIX - нач. $\mathrm{XX}$ вв. http://www.dissercat.com/content/semantika-krestyanskogo-doma-v-kulture-russkogo-severa-xix-nach-xx-vv.

Голубчикова В.Д., Хвтисиашвили 3.И.; Акбальян Е.Р. Северная энциклопедия. М.: Европ. изд.: Сев. просторы, 2004.

Гурвич И.С. (отв. ред.). Социальная организация и культура народов Севера. М.: Наука, 1974. 292 с. Санги В.М. (сост.) Легенды и мифы Севера: Сборник / вступ. статья А.В. Пошатаевой; худож. В. Петров. М.: Современник, 1985. 400 с.

Мурашко О.А. (сост.). Традиционные знания, культур и природопользование народов Севера. Серия: Библиотека коренных народов Севера, выпуск 11. М., 2005. 74 с.

Харючи Г.П. Традиции и инновации в этнической культуре ненцев, вторая половина XX в. http:www.dissercat.com/content/traditsii-i-innovatsii-v-etnicheskoi-kulture-nentsev-vtoraya-polovina-xx-v.

Хаснулин В.И. Современный взгляд на народную медицину Севера. Новосибирск, 1999. 281 с. Чаган В.И. От Дивногорска до Диксона. Красноярск: Красноярское кн. изд-во, 1976. 184 с.

Яптунэ Р. Как лечили наши предки: [О самобытных способах врачевания: прижигание, иглоукалывании, массаже] // Таймыр. 2001. 6 февр.

Яптунэ Р. Народная медицина: Чем и как лечатся в тундре // Вестник, 2004. № 6.

\section{References}

Borodina, A.B. 2012. Esteticheskii analiz dekorativno-prikladnogo iskusstva russkogo Severa 
[Aesthetic analysis of arts and crafts of the Russian North. Abstract]. PhD diss., Moscow: ROS. state University of Tourism and Service.

Vasilenko, B.I. 1987. Narodnaia meditsina i okhrana zdorov'ia (na primere Iamalo-Nenetskogo avtonomnogo okruga) [Traditional medicine and health protection (on the example of the Yamalo-Nenets Autonomous Okrug)]. PhD diss., Moscow.

Ivanova, V.S. 2009.Obriadnost' severnykh mansi v kontse XIX - nachale XXI veka: lokal'nye osobennosti [Ritualism of the northern Mansi in the late XIX - early XXI century: local features] PhD diss., St. Petersburg: Museum of Anthropology and Ethnography Peter the Great (Kunstkamera) RAS.

Redansky, V.G. (ed.). 2005. Dikson - snezhnoi Arktiki stolitsa: sbornik statei [Dixon - The Arctic Snow Capital: A Collection of Articles]. Moscow: Krasnoyarsk Book Publishing House, 176 p.

Voshchenkova, V. (ed.); Lazarev S. (foto). 1997. Gorod pod poliarnoi zvezdoi: Al'bom. 1667-1997 [Dudinka. City under the polar star: Album]. 1667-1997. M .: Polygraph video, 1997.

Sakieva A.A., N.O. Yurchenko, and A.N. Popova. 2005. Korennye malochislennye narody Taimyra: traditsii, byt, kul'tura: Rekomendatel'nyi ukazatel' literatury [Indigenous peoples of Taimyr: traditions, way of life, culture: A recommendatory index of literature]. Krasnoyarsk: LLC Publishing House Krasnoyarsk Writer.

Krivonogov, V.P. 1998. Etnicheskie protsessy u malochislennykh narodov srednei Sibiri [Ethnic processes in small peoples of central Siberia]. Krasnoyarsk: publishing house of KSPU.

Sangi B.M. (ed.) 1985. Legendy i mify Severa: Sbornik [Legends and Myths of the North: Compilation], entry article by A. V. Poshataeva; the artist V. Petrov. Moscow: Sovremennik.

Slavin S.V. (ed.). 1982. Letopis' severa. Sbornik po voprosam istorii ekonomicheskogo razvitiia i istoricheskoi geografii Severa [Chronicle of the north. Collection on the history of economic development and historical geography of the North] Vol. 10. Moscow: Publishing house "Thought", S. 31 - 32.

Lurie, S.V. 1997. Istoricheskaia etnologiia: ucheb. posobie dlia vuzov [Historical Ethnology: Textbook. manual for universities]. Moscow: Aspect-Press, $448 \mathrm{~s}$.

Maynicheva, A.Yu. Russkie Sibiri: zodchestvo v aspekte etnokul'turnoi adaptatsii. XVII - XX vv. [Russian Siberia: architecture in the aspect of ethnocultural adaptation. XVII - XX centuries]. http: www.dissercat.com/content/russkie-sibiri-zodchestvo-v-aspekte-etnokulturnoi-adaptatsii-xvii-xx-vv.

Messhtyb, N.A. 1999. Rastitel'nyi mir v aborigennykh kul'turakh Arktiki (po polevym materialam) [Plant world in native cultures of the Arctic (based on field materials)]. Sibirskii etnograficheskii sbornik. Issue 9, 72-73. Moscow.

Nikonova, L.I. et al. 2007. Mordva iuga Sibiri [Mordva from the south of Siberia] / edited by V.A. Yurchenkova; L.I. Nikonova. Saransk: Research Institute of Humanities Sciences under the Government of the Republic of Moldova.

Balashov, V.A. (ed.), Bryzhinsky V.S., Efimov I.A. 1995. Mordva: Istoriko-kul'tur. ocherki [Mordva: Historical and Cultural. Essays]. Saransk: Mordov. Prince Publishing House.

Mukhachev, A. 2002. Narodnoe vrachevanie nentsev: (Narodnye metody lecheniia boleznei nentsami) [Folk healing of the Nenets: (Folk methods of treating diseases of the Nenets)]. Mir Severa 5: 72-75.

Nikonova L.I., L.N. Schankina, N.N. Avdoshkina, and V.P. Savka. 2010. Mordva Dal'nego Vostoka [Mordva of the Far East], edited by V.A. Yurchenkova;. Saransk: Research Institute of Humanities. Sciences under the Government of the Republic of Moldova.

Nikonova L.I., L.N. Schankina, T.V. Garmaeva. 2010. Mordva tsirkumbaikal'skogo regiona i Respubliki Khakasiia [Mordva of the Circumbaikal region and the Republic of Khakassia], edited by. V.A. Yurchenkova L.I. Nikonova. Saransk: Research Institute of Humanities under the Government of the Republic of Mordovia.

Nikonova L.I., L.N. Schankina, Zh.V. Sherstobitova. 2009. Mordva Zapadnoi Sibiri: v 2 vol. Vol. 1. Selo Kalinovka: sibirskaia istoriia i mordovskie traditsii [Mordva of Western Siberia: at 2 part. 
Part 1. Kalinovka Village: Siberian History and Mordovian Traditions], edited by V.A. Yurchenkova. Saransk.

Permilovskaya, A.B. 2004. Semantika krest'ianskogo doma v kul'ture Russkogo Severa: XIX-nach. $X X v v$. [The semantics of the peasant house in the culture of the Russian North: XIX - beginning. XX centuries]. PhD diss. St. Petersburg: St. Petersburg state University of Culture and Arts.

Golubchikova V.D., Z.I. Khvtisiashvili; and E.R. Akbalyan (eds.). 2004. Severnaia entsiklopediia [Northern Encyclopedia]. Moscow: Europe. ed.: North open spaces,

Gurvich, I.S. (ed.). 1974. Sotsial'naia organizatsiia i kul tura narodov Severa [Social organization and culture of the peoples of the North]. Mosow: Nauka.

Sangi, V.M. (comp.) 1985. Legendy i mify Severa: Sbornik [Legends and myths of the North: Compilation]. Moscow: Sovremennik.

Murashko, O.A. (comp.). 2005. Traditsionnye znaniia, kul'tur i prirodopol'zovanie narodov Severa [Traditional knowledge, cultures and nature management of the peoples of the North]. Seriia: Biblioteka korennykh narodov Severa, vypusk 11 [Series: Library of Indigenous Peoples of the North, issue 11]. Moscow.

Kharyuchi, G.P. 1999. Traditsii i innovatsii v etnicheskoi kul'ture nentsev, vtoraia polovina XXv. [Traditions and innovations in the ethnic culture of the Nenets, the second half of the XX century]. PhD diss., Tomsk.

Khasnulin, V.I. 1999. Sovremennyi vzgliad na narodnuiu meditsinu Severa [A modern look at traditional medicine of the North]. Novosibirsk.

Chagan, V.I. 1976. Ot Divnogorska do Diksona [From Divnogorsk to Dikson]. Krasnoyarsk: Krasnoyarsk Prince Publishing House.

Yaptune, R. 2001. Kak lechili nashi predki: (O samobytnykh sposobakh vrachevaniia: prizhiganie, igloukalyvanii, massazhe) [How our ancestors treated: (On the original methods of healing: cauterization, acupuncture, massage)]. Taimyr 6.

Yaptune, R. 2004. Traditional medicine: What and how are treated in the tundra. Vestnik 6.

\section{Nikonova, Liudmila Ivanovna}

\section{Organization of life activity and formation of mordvin population in the Far North: the results of an ethnographic expedition}

Abstract. The Far North is a multicultural region, where peoples of different nationalities live, including the Mordvins. On September 22-October 4, 2013, an ethnographic expedition was conducted along the route: Kayerkan, Dudinka, Norilsk, Dixon. The expedition team (Nikonova L.I. - head, Okhotina T. N., Fadeeva M.M. - participants) collected data on the history of development of the region, interviewed informants according to the outline plan of ethnographic research, took photographs (informants, documents, statistics). Mordovian settlers managed to preserve aspects of traditional culture, mainly due to the constant connection with the Republic of Mordovia. Traditions manifest themselves in national dishes, rites, although innovations have also been introduced. The climate of the north affected social behavior and ethnic specificity, when cultural and economic phenomena (crafts and occupations) and material culture (housing, clothing, food, traditional knowledge) were subject to physical-geographical and environmental conditions. This resulted in modifying traditions, which can be considered as adaptation of the Mordvins in the Arctic.

Key words: Arctic and Far North territories, the Mordvins, relocation history, expedition, historical and ethnographic research, traditions, innovations 


\section{ОБЗОРЫ И РЕЦЕНЗИИ}

УДК $39+930.23$

DOI: $10.33876 / 2311-0546 / 2020-50-2 / 286-291$

(C) С.А. Арутюнов

\section{ПАМЯТНИК ВНУКАМ АРМЕНИИ - СЫНАМ РОССИИ. РЕЦЕНЗИЯ НА КНИГУ: А.Е. ТЕР-САРКИСЯНЦ. АРМЯНЕ РОССИИ И СОПРЕДЕЛЬНЫХ ТЕРРИТОРИЙ. ИСТОРИЯ В БИОГРАФИЯХ. М.: РУССКАЯ ПАНОРАМА, 2019.959 с.*}

Публикуемая здесь рецензия была написана в августе 2019 г. и оставалось лишь уточнить у автора рецензируемой книги, Аллы Ервандовны Тер-Саркисянц, некоторые вопросы технического характера, главным образом, о соотношении числа лиц, чьи краткие биографии были включены в ее текст, и общее количество упоминаемых в книге персонажей. Но буквально на следующий день после того, как в написанном тексте рецензии была поставлена последняя точка, пришло известие о ее совершенно неожиданной и безвременной кончине.

А.Е. Тер-Саркисянц была плодовитым автором. Список ее печатных трудов можно найти в рецензируемой книге, где он занимает страницы с 947 по 959 и насчитывает 18 книг и брошюр, плюс 210 статей, тезисов докладов, рецензий и других публикаций. Некоторые из них - это краткие статьи по 2-3 стр., но главные труды Аллы Ервандовны (далее А.Е.) выделяются на общем фоне отечественных монографических этнолого-исторических публикаций свои поистине титаническим объемом. Это книги «Армяне. История и этнокультурные традиции» (397 с.), «История и культура армянского народа» (686 с.), «Армяне Нагорного Карабаха» (958 с.) и рецензируемая книга, как уже указано, 959 с., плюс 56 с. иллюстраций.

Как ясно из подзаголовка книги, главное ее содержание составлено из биографических справок о тех сынах и дочерях армянского народа, которые либо родились, либо жили и творили на территории России (Российской империи и некоторых сопредельных территорий), но не включает данных о выдающихся армянах, чья жизнь протекала в самой Армении. Также почти не вошли в эту книгу армяне-уроженцы и резиденты Украины, Белоруссии, Молдовы и стран Балтии, хотя армяне-уроженцы и постоянные жители Грузии, Восточного Закавказья (советский период Азербайджанской (СР), а также республик Средней Азии и Казахстана в категорию армян сопредельных территорий включены. В книге имеется указатель имен, занимающий страницы с 811 по 880. Этот указатель охватывает не только армян, но и вообще всех людей, упоминаемых в книге, включая и персонажей глубокой древности, но все

Арутюнов Сергей Александрович - член-корреспондент РАН, главный научный сотрудник, зав. сектором Кавказа ИЭА РАН (Москва, Ленинский просп., 32-А). Электронная почта: gusaba@iea.ras.ru Arutyunov, Serge A. - Institute of Ethnology and Anthropology, RAS (Moscow, Leninsky prospect, 32a).e-mail: gusaba@iea.ras.ru

* Публикуется в соответствии с планом научно-исследовательских работ Института этнологии и антропологии РАН 